\title{
An Investigation of Genetic Polymorphism In The Rs35521 Serotonin Transporter Gene In Allergic Rhinitis
}

\author{
İsmail Salcan', Sara Salcan², Haktan Bağıs Erdem³, Suphi Müderris \\ 1 Erzincan Binali Yıldırım University Medical Faculty, Mengücek Gazi Education and Research Hospital, ENT Department, Erzincan-Turkey \\ Ismail Salcan ORCID ID: 0000-0001-8034-1064 \\ Suphi Müderris ORCID ID: 0000-0001-6425-1421 \\ 2 Erzincan Binali Ylldirtm University Medical Faculty, Department of Public Health, Erzincan, Turkey \\ ORCID ID: 0000-0001-5049-1838 \\ 3 Atatürk University Medical Faculty, Medical Genetics Department, Erzurum - Turkey \\ ORCID ID: 0000-0002-4391-1387
}

\begin{abstract}
Objective: Allergic rhinitis (AR) is one of the most frequently encountered allergic disorders and has a typical prevalence of between 18 and $40 \%$. The factors which underlie allergic disorders may vary since they are linked to climate, geography, different social conditions and genetic makeup. The objective of our research was to investigate any connections between polymorphism in the serotonin transporter gene and allergic rhinitis.
\end{abstract}

Methods: This study involved the participation of two groups aged between 15 and 60 years of age who attended the ENT clinic of the Medical Faculty at Erzincan University: 100 individuals with allergic rhinitis plus a control group of 200 individuals who lacked the condition. The AR cases were established on the basis of history, physical examination and skin prick testing. Peripheral blood samples were taken from both groups and subjected to genetic analyses. The analysis utilised a 5-HTT Taqman $®$ primer as genetic probe. The Chi-squared method was utilised for statistical analysis.

Results: 129 of the participants were female $(64.5 \%)$ and $71(35.5 \%)$ male. The average age of those participating was $34.5 \pm 14.6$ (range: $20-65$ ) years. In reference to the sex distribution of the patients, $79 \%$ of the patients were female. There was a significant difference between the groups according to sex $(p<0.01)$. No significant differences were noted between the patient and control groups when compared according to genetic polymorphism or place of residence. In $61 \%$ of the allergic rhinitis sufferers, their symptoms were seasonal. The incidence of $A R$ was higher in both females and in those living in an urban rather than rural setting. When the polymorphism is examined in both the patient and control groups, the most common type is the mutant type. In both the cases and controls, when the polymorphism was investigated, the most frequently seen type was the Mutant variety and no signi0cant difference in frequency was noted according to sex or place of residence.

Conclusion: In this study, when the cases and controls were compared in terms of the polymorphism in the rs35521 serotonin transporter gene, there was no difference at the level of statistical significance between the frequency of occurrence of the mutant or heterozygote form of the gene.

Keywords:Allergic rhinitis, serotonin, serotonin transporter, genetic polymorphism
Correspondence: İsmail Salcan

Erzincan Binali Yıldırım University Medical Faculty, Mengücek Gazi Education and Research Hospital, ENT Department, Erzincan-Turkey

Received: 08.06.2019; Accepted: 16.07.2019
Online available at: www.entupdates.org

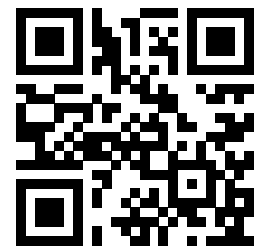




\section{Introduction}

Allergic rhinitis (AR) is characterised by signs such as sneezing, nasal congestion and rhinorrhoea. It is one of the most frequently encountered of the atopic conditions. In clinical terms, it is a type of hypersensitivity reaction dependant on specific IgE (immunoglobulin E) caused by the nasal mucosa coming into contact with an allergen. It is defined as a symptomatic inflammatory disorder affecting the nose. $\operatorname{IgE}$ acts upon basophils and eosinophils to stimulate the release of chemical mediators, resulting in mucosal oedema, increased secretion of mucus, vasodilation and increased vascular permeability. These events lead to symptoms such as nasal congestion, serous discharge and sneezing, which negatively impact the quality of life of AR sufferers. ${ }^{[1]}$

Whilst the precise aetiology of asthma, allergic reactions and other atopic disorders remains unknown, it is generally accepted that these diseases occur as a result of an interaction between genetic and environmental factors. ${ }^{[2]}$ Although the role of genetic factors in allergic disorders is controversial, the existence of environmental aetiological factors has been known about for a considerable period. Infections, exposure to cigarette fumes, air pollution and allergens both within and outside the home, and encountering proteins of extraneous origin, principally cow's milk, at an early age, are some of the known risk factors. ${ }^{[3,4]}$

$\mathrm{AR}$ is a significant clinical problem, since it is a disorder of high prevalence which demonstrates a low rate of remission in spite of treatment, and because of its co-occurrence with asthma. In the majority of industrialised populations, it is found to be a hypersensitivity to environmental allergens in over $25 \%$ of cases. The prevalence of allergic disorders is reported to have gone up within the last 50 years. ${ }^{[5]}$

In individuals with a genetic predisposition, sensitisation takes place following contact with an allergen. At that point, there is nothing in the patient's clinical condition to indicate the existence of allergic rhinitis. Only if contact with the same allergen is maintained do symptoms develop. The allergen initiates the immune response by entry into the mucosa followed by binding to the specific $\mathrm{IgE}$ carried on mast cells. The initial release of histamine and serotonin by mast cells is followed by other chemical messengers, such as tryptase and kinase. ${ }^{[6]}$

It has been demonstrated that chemical mediators such as histamine and serotonin $(5-\mathrm{HT})$ have a prominent role in the development of AR. Serotonin is involved in a multiplicity of physiological roles within the body and exerts its effects through 14 types of receptor specific to particular tissues. It plays a role in allergic inflammation as it is stored in basophils, platelets and mast cells. 5-HT is released into the synapse by cerebral neurons, then effectively cleared from the synaptic gap by the sodium and chloride ion-dependent high-affinity serotonin transporter (5-hydroxytryptamine transporter, 5-HTT, SERT) protein, which is localized to the presynaptic neuronal membrane and is encoded by the SLC6A4 gene. ${ }^{[7]}$ Thus the synaptic activity of serotonin is terminated by the transporter protein and neurotransmitter is returned to the pool for re-use. In other words, the 5HTT molecule has a key role in serotonin reuptake and regulating serotonergic function. The level of unbound serotonin circulating in the plasma is controlled by SERT located on cell membranes. Abnormal function of this protein may produce pathophysiological alterations as a result of fluctuations in the level of unbound serotonin. ${ }^{[8]}$

Given the vital part it plays in serotonergic function, in this research we aimed to clarify whether there is a relationship between the polymorphic variants of the 5HTT molecule and the aetiology of AR.

\section{Methods}

\section{Location and sampling method}

The research was undertaken at the ENT polyclinic attached to the Medical Faculty of the Binali Yildirim University in Erzincan, Turkey. There were two groups, each consisting of 100 individuals aged above 15 years. The cases group had a diagnosis of AR, whilst the controls were healthy.

Ethical approval to proceed was obtained from the Ethics Committee of the University Medical Faculty. Genetic analyses were supported by a grant from the Erzincan University Scientific Projects Commission.

The cases consisted of patients who were attending the ENT Clinic attached to the Medical Faculty of Erzincan University with a complaint of rhinitis. These individuals had their history taken using a form as well as undergoing nasal endoscopy and a detailed ENT physical examination. If rhinitis was clinically apparent and hypersensitivity to at least one allergen was apparent on skin prick testing, the diagnosis of $\mathrm{AR}$ was assigned and the individual joined the cases group. Circulating venous blood samples $(2 \mathrm{~mL})$ were then taken in an FBC tube from both the cases and control individuals, to be sent for genetic analysis. Whilst the samples were being transported to the biochemical 
laboratory of the hospital, they were kept at minus 20 Celsius.

\section{Skin prick testing}

Skin prick testing was performed on all the individuals involved in the study, from both the control and cases groups.

The skin prick testing was carried out on individuals who had no history of using antihistamines, local or systemic corticosteroids, any immunosuppressive agent or any acute infection within the previous ten days. The same researcher carried out all the tests and they were done at the same time each day.

Allergopharma allergen extracts were utilised for the test. Prior to the test, the skin was disinfected in an appropriate fashion and the areas to test demarcated using a pen at $2-3 \mathrm{~cm}$ intervals. To administer the test, the upper layer of skin was pierced using a device with a sharp tip. The skin was penetrated to a depth of $1 \mathrm{~mm}$ at an angle of approximately 45 degrees, which produced a scratch in the upper layer of the skin when the epidermis was punctured. This was the method used to ensure contact between the epidermis and the antigen. A solution containing antigen was then dripped onto the area overlying the skin puncture. After waiting for 15-20 minutes, the results could be interpreted. To prevent the possibility of cross-contamination, a separate lancet was used for each application. The evaluation depended on whther an indurated area was produced and if so, what its diameter was.

\section{Molecular DNA analysis}

1) 20 microlitres of proteinase $K$ was pipetted into a $1.5 \mathrm{~mL}$ or $2 \mathrm{~mL}$ microcentrifuge tube. Then $5-10$ microlitres of uncoagulated blood from the samples were added to the tube. The total volume of liquid within the microcentrifuge tube was made up to 220 microlitres by adding PBS solution. In order to obtain material for DNA free isolation, 4 microlitres of a solution of $100 \mathrm{mg} / \mathrm{mL}$ RNase A were added and the contents vortexed. Following this the tubes were incubated at room temperature for 2 minutes.

2) After adding 200 microlitres of AL buffer minus ethanol the tubes were again vortexed and incubated for 10 minutes at +56 Celsius.

3) 200 microlitres of ethanol (96-100\%) were mixed in, using the vortex mixer.

4) The mixture produced by the third step in the procedure was then transferred using a pipette to a 2
$\mathrm{mL}$ capacity DNeasy mini spin column. It was spun at above $6000 \mathrm{~g}(8000 \mathrm{rpm})$ for one minute. The leftover material from centrifugation was then discarded.

5) The DNeasy mini spin column contents were transferred to a new $2 \mathrm{~mL}$ capacity test tube and 500 microlitres of AW1 buffer added. Again it was centrifuged at above $6000 \mathrm{~g}(8000 \mathrm{rpm})$ for one minute. The leftover material from centrifugation was then discarded.

6) The DNeasy mini spin column contents were transferred to a new $2 \mathrm{~mL}$ capacity test tube and 500 microlitres of AW2 buffer added. Again it was centrifuged at above $20000 \mathrm{~g}(14000 \mathrm{rpm})$ for three minutes. The leftover material from centrifugation was then discarded.

7) The DNeasy mini spin column contents were transferred to a new $2 \mathrm{~mL}$ capacity test tube. 200 microlitres buffer was added using an AETNAeasy membrane pipette. After incubating the prepared material at room temperature for one minute, it was centrifuged at greater than $6000 \mathrm{~g}(8000 \mathrm{rpm})$ for one minute.

8) The samples for research were then stored at minus 20 Celsius until needed.

Quantitative measurement of the concentration of DNA isolated by means of spectrophotometry.

1) The DNA samples were then diluted to a level of $1 / 600$ and the values for absorbance at the wavelengths of $260 \mathrm{~nm}$ (for DNA) and 280nm (for protein) were measured using the ultraviolet spectrophotometer.

2) The DNA concentration of the samples was calculated from the absorbance value at $260 \mathrm{~nm}$. The DNA needs to be at an appropriate level of purity for a satisfactory PCR result to be obtained.

3) To prepare the DNA samples for the polymerase chain reaction, the DNA was diluted using DNA hydration solution at a strength of $50 \mathrm{ng} / \mu \mathrm{L}$. For each sample, the readings were taken twice and in this way the DNA purity level was checked and the result quantified.

4) In samples where the concentration of DNA was low, the procedure was repeated up to the point where an acceptable level had been obtained.

\section{5-HTT genetic polymorphism study}

Specifically optimised primers were prepared for the study. The NCBI (National Center for Biotechnology Information) database was consulted regarding the 5-HTT rs35521 protein and information sought on G>A 


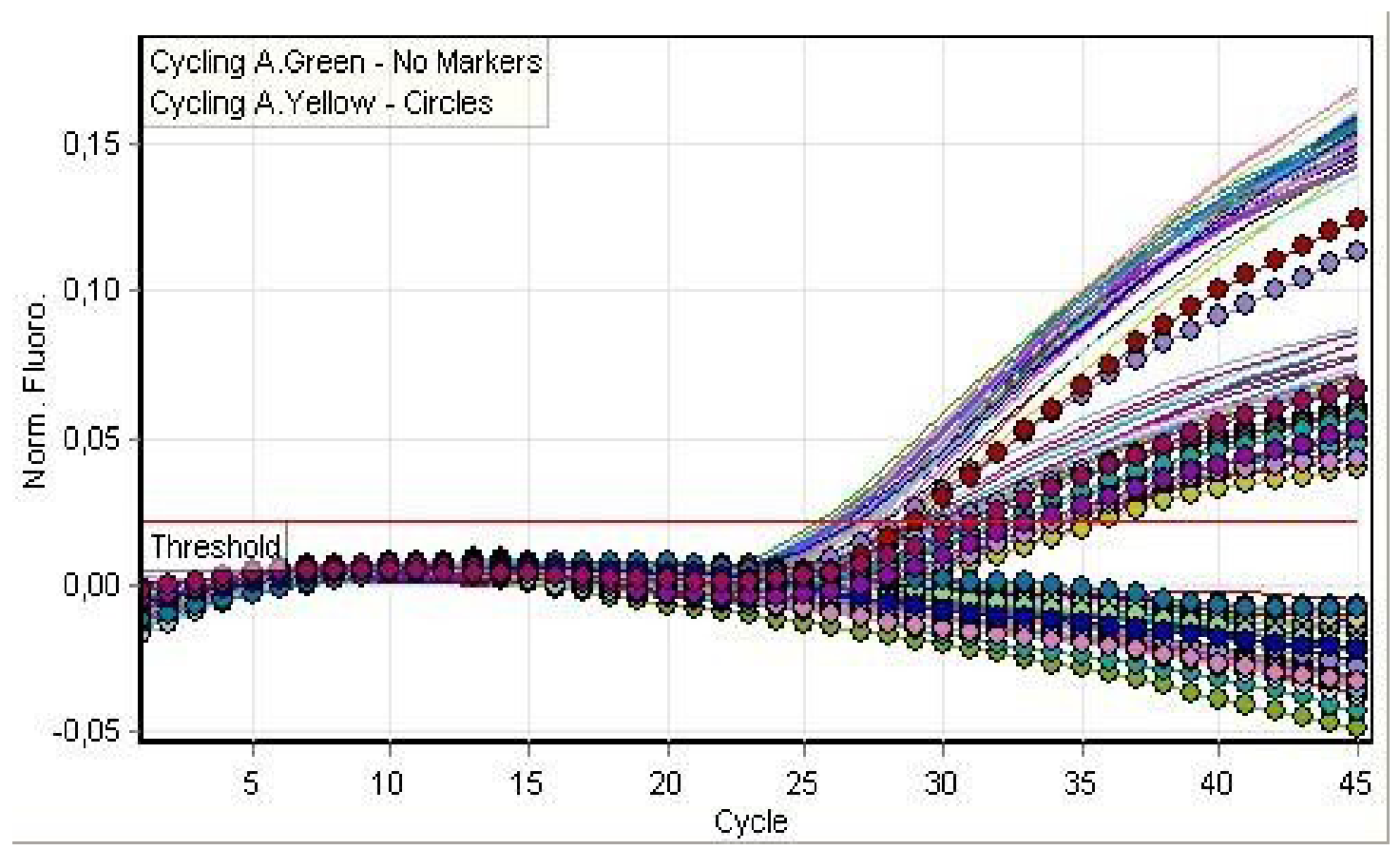

Figure 1. Analysis of the samples for 5-HTT Gene Polimorphism

single nucleotide polymorphisms using the reference NC_000005.10:107745777 and the GRCh38.p7 software version. Primers were constructed as follows: for the forward direction - 5'ATGCCAGCACCTAACCCCTAATGT3' and the reverse - 5'GGACCGCAAGGTGGGCGGGA3'.

One $0.2 \mathrm{~mL}$ PCR tube was labelled for each individual. A total volume of $20 \mu \mathrm{L}$ was set aside for the polymerase chain reaction. Heterozygous and mutant control DNA samples were used in this study. The primers and heterozygous / mutant controls were diluted with 500 microlitres of RNase-free water before use. The primer / probes were diluted with 65 microlitres of RNase-free water. The samples were incubated for $5 \mathrm{~min}$ then vortexed. The heterozygous / mutant controls were diluted 1/10 before use.

\section{Analysis of results}

The wild probe (GG genotype) is labeled in the ROX (orange) channel and the mutant probe (AA genotype) is labeled in the VIC (yellow) channel. If the sequence is a wild type, a strong amplification graph is detected in the ROX channel and no signal or only a very low level one is detected in the VIC channel. The mutant type produces the opposite. In heterozygotes (GA genotype), an average sig- nal level is determined in both (ROX and VIC) channels.

\section{Statistical analysis}

The data gathered were evaluated and analysed using the SPSS for Windows statistical application version 21.0. Numerical variables were expressed as mean and standard deviation, whilst categorical variables were expressed as absolute values and percentages. In the statistical evaluation of the data, the chi-squared test was utilised for categorical variables. A p value of less than 0.05 was set as the level needed to achieve statistical significance.

\section{Results}

The sample consisted of 100 cases and 100 controls (200 individuals in total), of whom $129(64.5 \%)$ were female and $71(35.5 \%)$ were male. The average age of those taking part was $34.5 \pm 14.6$ (range: $20-65$ ) years.

The sex distribution between the groups is presented in table 1 . When the sex distribution is examined in the cases group, it can be seen that $79 \%$ of the sample consisted of women. The sex difference between the groups reached statistical significance $(\mathrm{p}<0.01)$. 


\begin{tabular}{lcccc}
\hline \multicolumn{4}{l}{ Table 1. Age and sex distribution of groups } \\
\hline \multicolumn{4}{c}{ Female $\mathrm{n}(\%)$} & \multicolumn{2}{c}{ Male $\mathrm{n}(\%)$} \\
\hline Patient & 79 & $(79)$ & 21 & $(21)$ \\
$\begin{array}{l}\text { Control } \\
\text { Total }\end{array}$ & 50 & $(50)$ & 50 & $(50)$ \\
& 129 & $(64.5)$ & 71 & $(35.5)$ \\
\hline
\end{tabular}

$\chi 2=18,3 p<0,01$

When the age distribution between the two groups were compared, it was noted that the average age of the cases was 41.5 years, whilst that of the controls was 27.5 years.

When both groups are compared in terms of their usual place of residence, it was observed that $72 \%$ and $70 \%$ of the cases and controls were living in an urban setting, respectively. There was no statistically significant difference between the groups in this regard. For the cases group, $61 \%$ had symptoms with a seasonal pattern and $39 \%$ were perennial, it was noted.

In the cases group, there was a higher frequency of AR symptoms in females compared to males, as is evident in table 2, and those living in the urban setting were found to be more symptomatic than those living in the countryside.

\begin{tabular}{|c|c|c|c|c|}
\hline \multirow[b]{2}{*}{ Sneezing } & \multicolumn{2}{|c|}{ Female n (\%) } & \multicolumn{2}{|c|}{ Male n (\%) } \\
\hline & 60 & (75.9) & 19 & (24.1) \\
\hline Nasal Discharge & 33 & (78.6) & 9 & (21.4) \\
\hline Nasal stiffness & 15 & (75) & 5 & (25) \\
\hline Itching & 46 & $(82.1)$ & 10 & (17.9) \\
\hline Eye symptoms & 6 & $(66.7)$ & 3 & (33.3) \\
\hline Post nasal discharge & 27 & (90) & 3 & (10) \\
\hline
\end{tabular}

A comparison of the two groups in terms of the genetic polymorphism in the rs 35521 gene revealed that 875 of the cases and $78 \%$ of the controls carried the mutant genotype, but the difference between the groups in this respect did not reach the level of statistical significance (see table 3).
Table 3. rs 35521 polymorphism in patient and control groups

\begin{tabular}{lccccc}
\hline & \multicolumn{2}{c}{$\begin{array}{c}\text { Mutant } \\
(\mathrm{GG} \rightarrow \mathrm{AA})\end{array}$} & \multicolumn{2}{c}{$\begin{array}{c}\text { Heterozygous } \\
(\mathrm{GG} \rightarrow \mathrm{AG})\end{array}$} & $\begin{array}{c}\text { Statistical } \\
\text { Analysis }\end{array}$ \\
\cline { 2 - 6 } Group & \multicolumn{2}{c}{$\mathrm{n}(\%)$} & \multicolumn{3}{c}{$\mathrm{n}(\%)$} \\
Patients & 87 & 87 & 13 & 13 & $\chi 2=2.85$ \\
Control & 78 & 78 & 22 & 22 & $\mathrm{p}=0.09$ \\
Total & 165 & 82.5 & 35 & 17.5 &
\end{tabular}

Table 4 lists specific details of the patient group in terms of the rs35521 genetic polymorphism. As can be seen in the table, the most frequently observed variant was the homozygous mutant type, in both males and females.

\begin{tabular}{|c|c|c|c|c|}
\hline \multirow[b]{2}{*}{ Sex } & \multirow{2}{*}{$\begin{array}{c}\begin{array}{c}\text { Mutant } \\
(\mathrm{GG} \rightarrow \mathrm{AA})\end{array} \\
\mathrm{N}(\%)\end{array}$} & \multirow{2}{*}{$\begin{array}{c}\begin{array}{c}\text { Heterozygous } \\
\text { (GG } \rightarrow \text { AG) }\end{array} \\
\mathrm{N}(\%)\end{array}$} & \multicolumn{2}{|c|}{$\begin{array}{l}\text { Statistical } \\
\text { Analysis }\end{array}$} \\
\hline & & & $p$ & $\chi^{2}$ \\
\hline Female & 71 (89.9) & $8(10.3)$ & & \\
\hline Male & $16(76.2)$ & $5(23.8)$ & 0.09 & 2.74 \\
\hline \multicolumn{5}{|l|}{ Location } \\
\hline City Center & 64 (88.9) & $8(11.1)$ & & \\
\hline Village & $23(82.1)$ & $5(17.9)$ & 0.36 & 0.81 \\
\hline \multicolumn{5}{|l|}{ Symptom Period } \\
\hline Seasonal & $51(83.6)$ & $10(16.4)$ & & \\
\hline Perennial & $36(92.3)$ & $3(7.7)$ & 0.2 & 1.59 \\
\hline \multicolumn{5}{|l|}{ Symptoms } \\
\hline Sneezing & $67(84.8)$ & $12(15.5)$ & 0.2 & 1.59 \\
\hline Nasal discharge & $38(90.5)$ & $4(9.5)$ & 0.37 & 0.77 \\
\hline Nasal stiffness & $19(17.4)$ & $1(5)$ & 0.23 & 1.14 \\
\hline Itching & $51(91.1)$ & $5(8.9)$ & 0.17 & 1.86 \\
\hline Eye symptoms & $7(77.8)$ & $2(22.2)$ & 0.33 & 0.74 \\
\hline Post nasal drainage & $29(96.7)$ & $1(3.3)$ & 0.1 & 3.54 \\
\hline Wheezing & $5(100)$ & 0 & & \\
\hline Cough & $24(87)$ & $2(13)$ & 0.5 & 0.87 \\
\hline
\end{tabular}


There was no statistically significant difference according to sex in this variable. Neither was there any statistically significant difference according to place of residence for the genetic polymorphism. In both rural and urban dwellers, the most frequent genotype was the mutant variant.

Within the cases group, the most frequently observed genotype was the mutant variant, which had a frequency of $83.6 \%$ in those with seasonal and $92.3 \%$ in those with perennial symptoms. There was no statistically significant difference in terms of genotype when examined from the point of view of timing of symptoms.

In the cases group, when the frequency of symptoms was examined, the mutant genotype was the one most frequently encountered, but this difference was not statistically significant.

Within the control group, when the genetic polymorphism was compared between men and women, the most frequently occurring type was the mutant type, found in $84 \%$ of women and $72.5 \%$ of men. This difference lacked statistical significance. The mutant type was also the most common regardless of whether the individuals were urban or rural dwellers, and there was no statistically significant difference in this regard (see table 5).

\begin{tabular}{|c|c|c|c|c|c|}
\hline \multirow[b]{2}{*}{ Group } & \multicolumn{2}{|c|}{$\begin{array}{l}\text { Mutant } \\
(\mathrm{GG} \rightarrow \mathrm{AA})\end{array}$} & \multicolumn{2}{|c|}{$\begin{array}{l}\text { Heterozygous } \\
\text { (GG } \rightarrow \text { AG) }\end{array}$} & \multirow[t]{2}{*}{$\begin{array}{c}\text { Statistical } \\
\text { Analysis }\end{array}$} \\
\hline & $\mathrm{n}$ & $(\%)$ & $\mathrm{n}$ & $(\%)$ & \\
\hline Male & 36 & $(72.5)$ & 14 & (11.1) & $\chi 2=2.09$ \\
\hline Female & 42 & (84) & 8 & (16) & $p=0.14$ \\
\hline \multicolumn{6}{|l|}{ Location } \\
\hline City Center & 56 & (80) & 14 & (20) & $\chi 2=0.54$ \\
\hline Village & 22 & (73.3) & 8 & $(26.7)$ & $p=0.46$ \\
\hline Total & 78 & (78) & 22 & (22) & \\
\hline
\end{tabular}

The frequency of asthma in those taking part in the trial was observed to be $12 \%$. Some $91.7 \%$ of these asthma sufferers carried the mutant variant of the genetic polymorphism. There was no statistically significant difference observable in the asthmatic group in terms of the genetic result (see table 6).

\begin{tabular}{|c|c|c|c|c|c|c|c|}
\hline \multirow[b]{2}{*}{ Asthma } & \multicolumn{2}{|c|}{$\begin{array}{l}\text { Mutant } \\
(\mathrm{GG} \rightarrow \mathrm{AA})\end{array}$} & \multicolumn{2}{|c|}{$\begin{array}{l}\text { Heterozygous } \\
\qquad(\mathrm{GG} \rightarrow \mathrm{AG})\end{array}$} & \multicolumn{2}{|c|}{ Total } & \multirow[t]{2}{*}{$\begin{array}{c}\text { Statistical } \\
\text { analysis }\end{array}$} \\
\hline & $\mathrm{N}$ & $(\%)$ & $\mathrm{N}$ & $(\%)$ & $\mathrm{N}$ & $(\%)$ & \\
\hline+ & 11 & (91.7) & 1 & (8.3) & 12 & (6) & $\chi 2=0.74$ \\
\hline- & 154 & (81.9) & 34 & $(18.1)$ & 188 & (94) & $p=0,69$ \\
\hline Total & 165 & (82.7) & 35 & (17.5) & 200 & (100) & \\
\hline
\end{tabular}

\section{Discussion}

Allergic rhinitis (AR) is the most common amongst atopic disorders and is a somewhat common disease worldwide. It is known to affect $10-25 \%$ of the world's population and its prevalence shows an increasing tendency, especially in the last 10 years [9]. AR typically starts before the age of 40 and the mean age of onset is between 12 and 15. ${ }^{[10]}$ In our study, the average age of participants was $34.5 \pm 14.6$ (range: 20-65) years. This corresponds to what would be expected from the literature.

When the sex distribution of the cases and control groups was investigated, it was seen that $79 \%$ of the cases were female, and there was a statistically significant difference between cases and controls in this regard. In research carried out by Öztürk et al ${ }^{[1]}$, of 180 patients receiving a provisional diagnosis of AR, 105 were female and 75 male. The female to male ratio was found to be 1.4 to 1 . Nihlen et $\mathrm{al}^{[11]}$ reported that the women in their study were more troubled than the men by AR symptoms. In the research that has been carried out so far, AR has been found to be more common in women, and in our study, too, AR was more common amongst females, a result that was significant.

Asthma was found in $12 \%$ of the AR cases in the present study, but there was no statistically significant result observable in the genetic analysis with regard to whether the patients were asthmatic or not. Bousquet et al ${ }^{[12]}$ carried out research which looked at the frequency of occurrence of asthma in individuals with AR. Their control group contained 502 individuals, whilst there were 591 AR cases. $2 \%$ of the controls and $24 \%$ of AR sufferers were asthmatic 
The results they obtained are comparable with those seen in the present study.

Serotonin is a key molecule in the body, with 14 different receptors and with various physiological functions within different tissues. The research to date has produced important findings, particularly in reference to the effects of serotonin on the central nervous system. Catalano ${ }^{[7]}$ reported how serotonin, once it has been released into the synaptic gap is effectively cleared by the serotonin transporter protein located on the presynaptic neuronal membrane. In research undertaken by Lesch et al, it is supposed that polymorphism of the serotonin transporter gene may possibly affect the regulation of serotonin-linked behaviours, in particular certain psychiatric disorders such as anxiety, depression, schizophrenia, autism, bipolar affective disorder and seasonal affective disorder. ${ }^{[13]}$ However, a significant relationship was not observed in all of these disorders. In a study undertaken by Özkaya et al ${ }^{[14]}$ a group of 76 individuals suffering from Parkinson's disease was compared with 54 healthy individuals. Both groups were genotyped for the serotonin transporter protein. The relationship between disease and observed frequencies of the $\mathrm{L}$ and $\mathrm{S}$ alleles were investigated. The alleles were found to be present at similar rates in both cases and controls. No statistically significant relationship was reported from the statistical analysis.

Erdal et al. performed a study on 121 healthy, unrelated volunteers, which looked at the polymorphism within intron 2 of the variable number tandem repeat sequence in the 5-HTT protein and polymorphism of insertion/ deletion type in the transcriptional control region of the gene (5HTTLPR). Using PCR to genotype the polymorphic regions of this gene, they looked at genetic frequencies. The following results were obtained: 63 individuals $(52.07 \%)$ had the genotype $12 / 12 ; 51$ individuals $(42.15 \%)$ had the genotype 12/10; and 7 individuals had the genotype 10/10. These results were not found to be statistically significant. In a German study carried out by Collier et al ${ }^{[16]}$, the frequency of the L allele of the 5-HTT gene was found to be 0.60 , the $S$ allele having a frequency of 0.40 .

Karakülah ${ }^{[17]}$ researched genetic frequencies in the 5HTTLPR genetic polymorphism in case and control groups. For the $\mathrm{L}$ allele, the control group frequency was $49.3 \%$ and the case group frequency $50 \%$; for the S allele, the controls had a frequency of $50.7 \%$ and the cases a frequency of $50 \%$.No statistically significant difference was observed $(\mathrm{p}=0.835)$. For the smokers in the sample, the $\mathrm{S} /$ $\mathrm{S}$ genotype was found in $27.8 \%$, the S/L genotype in $45 \%$ and the L/L genotype in $27 \%$. For the control group, $26.9 \%$ of individuals had the genotype $\mathrm{S} / \mathrm{S}, 47.8 \%$ the genotype $\mathrm{S} / \mathrm{L}$ and $25.4 \%$ the genotype $\mathrm{L} / \mathrm{L}$. There was no statistically significant difference between these groups ( $\mathrm{p}=0.861$ ). Possession of the $\mathrm{L}$ allele was $72.1 \%$ in the group of smokers and $73.7 \%$ in the control group, a result that lacked statistical significance ( $>0.05)$. For possession of the $\mathrm{S}$ allele, the group of smokers had the gene at a frequency of $73 \%$ and it was present in $74 \%$ of the controls. This result also lacked statistical significance $(\mathrm{p}=0.368)$.

The rs 35521 polymorphism was examined in our study and the homozygous mutant form discovered in $87 \%$ of the cases group and $78 \%$ of the controls, a result that was not found to show difference at the level of statistical significance. In the literature we reviewed there is no previous study investigating the serotonin transporter gene and AR.

Farjadian et al ${ }^{[18]}$ investigated 100 cases of asthma alongside a control group of 100 individuals. When they compared the groups for the same rs35521 polymorphism we examined, they found no relationship with asthma of mild or moderate degree beginning in childhood.

In both the control and cases groups involved in our research, when the polymorphism is compared in men and women, the most frequently occurring genotype in bothe sexes is the homozygous mutant variant. There was no significant difference observable between the sexes. When the frequency of rs35521 was compared in rural and urban dwellers, the homozygous mutant type was again the most frequently occurring in both groups and there was no signifcant difference between groups. Considering the symptomatic course in the individuals comprising the cases group, we find that the homozygous mutant form is the most common variant, being found in $83.6 \%$ of cases with a seasonal pattern and $92.3 \%$ of the perennial cases. There was no significant difference in gene occurrence according to pattern of symptoms.

When the case and control groups were examined with regard to whether they were homozygous or heterozygous mutant gene carriers for the 5-HTT gene, no significant differences were observed. Further studies involving greater numbers of patients will supply more information on the effects of the transport protein. 


\section{Conclusion}

Allergic rhinitis is a disorder with a generally high prevalence and a genetic basis. It has a connection with asthma. For these reasons it is a significant clinical problem.

\section{References}

1. Öztürk Ö, Tokmak A, Güçlü E, Yıldızbaş Ş, Gültekin E. Skin Prick Test Results of Patients with Allergic Rhinitis in Düzce. [Article in Turkish] Düzce Tip Fak Derg 2005;1:11-4.

2. Holgate ST. Genetic and environmental interaction in allergy and asthma. J Allergy Clin Immunol 1999;104:1139-46.

3. Cogswell JJ, Mitchell EB, Alexander J. Parental smoking, breast feeding, and respiratory infection indevelopment of allergic diseases. Arch Dis Child 1987;62:338-44.

4. Zeiger RS, Heller S, Mellon MH, et al. Effect of combined maternal and infant food-allergen avoidance on development of atopy in early infancy: A randomized study. J Allergy Clin Immunol 1989;84:72-89.

5. Floistrup H, Swartz J, Bergstrom A, et al. Allergic disease and sensitization in Steiner school children. J Allergy Clin Immunol 2006;117:59-66.

6. Cingi C, Oğhan F, Ünlü H, Tekat A, Okuyucu Ş. Efficacy of montelukast and desloratadine combination in allergic rhinitis. [Article in Turkish] $\mathrm{J}$ Med Updates 2011;1:3-16.

7. Catalano M. The challenges of psychopharmacogenetics. Am J Hum Genet 1999;65:606-10.

8. Murphy DL, Lerner A, Rudnick G, Lesch KP. Serotonin Transporter: Gene, Genetic Disorders, and Pharmacogenetics. Mol Interv 2004;4:109-23.

9. van Cauwenberge P, Bachert C, Passalacqua G, et al. Consensus statement on the treatment of allergic rhinitis. European Academy of Allergology and Clinical Immunology. Allergy 2000;55:116-34.

10. Rosenwasser LJ. Treatment of allergic rhinitis. Am J Med 2002;113:17-24.
In the present study, there was no statistically significant difference observable in the genotype of the rs35521 gene on the basis of sex, place of residence or duration of symptoms. We believe further studies involving greater numbers of patients are now required.

11. Nihlén U, Greiff L, Montnémery $P$, et al. Incidence and remission of selfreported allergic rhinitis symptoms in adults. Allergy 2006;61:1299-304.

12. Bousquet J, Annesi-Maesano I, Carat F, et al. Characteristics of intermittent and persistent allergic rhinitis: DREAMS study group. Clin Exp Allergy 2005;35:728-32.

13. Lesch KP, Bengel D, Heils A, et al. Association of anxiety-related traits with a polymorphism in the serotonin transporter gene regulatory region. Science 1996;274:1527-31.

14. Özkaya M, Doğu O, Sevim S, Çamdeviren H, Yalçınkaya D, Erdal ME. Serotonin transporter (SERT) gene polymorphism in Parkinson's disease. [Article in Turkish] Turkish J Neurol 2004;10:201-5.

15. Erdal ME, Herken H, Barlas Ö, Erdal N. Polymorphisms in the Serotonin Transporter Gene. [Article in Turkish] J Clin Psy 2000;3:192-6.

16. Collier DA, Stöber G, Li T, et al. A novel functional polymorphism within the promoter of the serotonin transporter gene: possible role in susceptibility to affective disorders. Mol Psychiatry 1996;1:453-60.

17. Karakülah K. Serotonin transporter gen polimorfizlerinin sigara bağımlılığı ve erişkin dikkat eksikliği hiperaktivite bozukluğu ile ilişkisi. Pamukkale Üniversitesi Tıp Fakültesi Ruh Sağliğı Ve Hastalıkları Anabilim Dalı. Uzmanlik Tezi Denizli 2013. http://acikerisim.pau.edu.tr/xmlui/ handle/ $11499 / 414$.

18. Farjadian S, Moghtaderi M, Fakhraei B, Nasiri M, Farjam M. Association between serotonin transporter gene polymorphisms and childhood asthma. J Asthma 2013;50:1031-5. 